\title{
Multi-group confirmatory factor analysis of the life attitude profile in Chilean adolescents
}

\author{
Patricia Imbarack Dagach ${ }^{1}$ (D) Cristian Brotfeld ${ }^{2}$ (D) Joaquín García-Alandete ${ }^{3}$ (D)
}

Accepted: 3 December 2020 / Published online: 7 January 2021

(C) The Author(s) 2021

\begin{abstract}
Adolescents are challenged to take decisions about issues associated to the vital circle and the comprehension of the world. Meaning in life (MiL) takes a leading role in adolescence. Reker and Peacock developed the Life Attitude Profile (LAP) for assessing MiL, and Erci developed a revised version (LAP-R). The main objective of this study was to analyze the factorial structure, reliability, invariance across gender, and absence/presence of assessment bias of a Spanish adaptation of the Turkish LAP-R among 2138 Chilean adolescents (1205 boys, 912 girls, and 8 others), who were studying in 3rd and 4th year. The LAP-R showed an acceptable structural validity, acceptable internal consistency, and invariance across gender. MiL as a significant domain of human experience in adolescents.
\end{abstract}

Keywords Adolescence $\cdot$ Meaning in life $\cdot$ Life attitude profile $\cdot$ Multi-group confirmatory factor analysis $\cdot$ Chilean

\section{Introduction}

\section{School and Development of Personal Identity in Adolescents}

The school plays an essential role facing students' vital questions and their suitable resolution, being called to support the decision of who have to fulfil a set of criteria to graduate and simultaneously succeed in other several domains of life, such as building intimacy and ideological beliefs, among others (Malika et al. 2013; Rodríguez and Padilla 2016).

Patricia Imbarack Dagach

paimbara@uc.cl

Cristian Brotfeld

cabrotfe@uc.cl

Joaquín García-Alandete

ximo.garcia@ucv.es

1 Department of Education, Faculty of Education, Pontifical Catholic University of Chile, Campus San Joaquín: Vicuña Mackenna 4860, Macul, Santiago de Chile, Chile

2 Department of Psychology, School of Psychology, Pontifical Catholic University of Chile, Santiago de Chile, Chile

3 Department of Neuropsychobiology, Methodology, and Basic and Social Psychology. Faculty of Psychology, Catholic University of Valencia Saint Vincent Martyr, Valencia, Spain
During secondary education, the students are challenged to take decisions about a countless number of issues, associated to the vital circle and the comprehension of the world (Lagos and Palacios 2008; Martínez 2007; Salvatierra et al. 2004; Weiss 2012). Expressions like "I would like to be" o "I would like to do" are part of their personal identity and exhibit their subjectivity, providing them with the opportunity to anticipate and project themselves through questions such as "Who am I? How do I fit? Where am I going in life?" (Zhang and Li 2016). With that, the students are building their self-awareness of insertion (inclusion and exclusion) into the labour market, constituting their occupational identity (Makola 2014).

\section{Meaning in Life and Development of Personal Identity in Adolescents}

The experience of meaning in life (MiL) is strongly relevant to the process of individuation, and the construction of identity allows to integrate and materialize dimensions such as past, present and future in a unit, which endows the sense of existence and thus provides the student with individual and collective alternatives of action. All this occurs in a particular scenario of development, such as adolescence, considered as a stage of normative crisis, which depends on a variety of factors that will give diverse characteristics to the teenage maturity. The secondary students reach puberty, a critical moment to configure the setting of their vision of the world and of life. 
MiL takes a leading role in adolescence, as it enables the young person to solve vital questions. MiL has been conceived as an asset for the positive development of youth, as it stimulates commitment with an adaptive purpose and, consequently, young people are expected to perform better in various dimensions of their social and affective life (GarcíaAlandete 2014; García-Alandete et al. 2019; Quiceno and Vinaccia 2014). So, MiL can be understood as a personal identity source with which the young build their future, and includes high levels of positive affection, pro-sociality and altruism, self-esteem, psychological well-being, resilience and perceived self-efficacy (Burrow and Hill 2011; Cotton et al. 2010; DeWitz and Woolsey 2009; White et al. 2010), and selection of opportunities for personal development (e.g. Damon et al. 2003), all of which are variables strongly correlated with academic performance (e.g. Burrow et al. 2010), and lower levels of depression, suicide and use of drugs and alcohol. (Hodges and Crowe 2014; Yeager and Bundick 2009).

\section{Measuring MiL: The Life Attitude Profile-Revised}

Reker and Peacock (1981) developed the Life Attitude Profile (LAP) for assessing MiL from logotherapeutic assumptions. This scale was created as a contribution to the understanding of the multidimensional nature of the sense of life. In the beginning, a scale of 56 items of seven points each (Likert scale) was created, and work was carried out with a sample of 219 secondary students. In the first analysis of the instrument, LAP was subjected to factorial analysis of the main components with varimax variation, with a minimum criterion of .33 to load an item to a factor. The final results reach seven factors with very adequate consistency coefficients, all between .50 and .70 (Reker and Peacock 1981).

The present study works with Reker's (1992) revised version of the LAP, the so-called Life Attitude Profile-Revised, LAP-R. While the seven dimensions of LAP were shown to be internally consistent, stable over time and valid measures of their respective constructions, lately, Reker (1992) proposed a personal-component model of a double component; purpose and coherence, which nowadays we know as Life Attitude Profile-Revised (LAP-R).

The LAP-R, which is based on a conceptualization of $\mathrm{MiL}$ as a personal attitude of engagement and self-realization, comprises 30 items for assessing six dimensions of MiL: Purpose (it refers to having goals and a mission in life, having a sense of direction through past, present and future), Coherence (intuitive comprehension of oneself, the others and life in general), Choosing or Responsibility (perception of freedom to make all life choices for oneself), Acceptance of Death (fearlessness of death and its acceptance as a natural aspect of life), Existential Vacuum (lack of sense and orientation in life), and Seeking for Goals (desire to make the most of one's life), all of which are responded on a Likert-type scale $(1=$ Strongly disagree, $7=$ Totally agree). Reker (1992) obtained an acceptable internal consistency for the LAP-R dimensions, $\alpha=.77$ to .91 .

Several studies have analyzed the psychometric properties of the LAP-R. Meraviglia (2004) found that the internal consistency and reliability of LAP-R subscales were acceptable, but not for the Existential Vacuum sub-scale that presented a low alfa. Mehnert and Koch (2008) worked with a sample of 511 German patients diagnosed with prostate cancer, with an average age of 64 years, $88 \%$ married and $66 \%$ with secondary education. The objective of this study was to evaluate the psychometric properties of the German adaptation of LAP-R in a sample of ambulatory prostate cancer. It confirmed five of the original six dimensions of the LAP-R, leaving the Purpose dimension outside the model. Except for the Purpose domain, a good adjustment was obtained between the original hypothetical dimensions of LAP-R and the empirically-derived factor structure in German in the sample of cancer patients. However, the Purpose and Coherence domains were not completely different $(r=.72)$. Most of the LAP-R scales showed good internal consistency, with a Cronbach's alpha between .80 and .82 , while the reliability for the Existential Vacuum and the Seeking for Goals was acceptable (.69 and .74 respectively).

Erci (2008), in a sample of 199 Turkish patients diagnosed with cancer, found that the Cronbach's alpha for the Acceptance of Death and Existential Vacuum domains were lower than .70, whereas the Cronbach's alpha for Purpose, Coherence, Choosing or Responsibility, and Seeking for Goals was between .73 and .82 , so he evaluated the internal structure of the LAP-R using only the items of these dimensions, obtaining a factorial solution according to the theoretical model that explained $46.91 \%$ of the total variance and showed acceptable item-test correlations.

The discrepancies between the studies on the factorial structure of LAP-R suggest the need for an evaluation that accounts for cross-cultural elements and the particularities of the implementation of LAP in populations without pathology. Along these lines, the LAP-R (Reker, 1992) seems to better fit the reality of adolescents, who are a segment of the population which has never been studied with this scale. Ackerman (2013) investigated the use of LAP-R in 68 students of low socioeconomic status in Texas schools, reporting that its usefulness is even more pertinent in adolescents than other meaning scales, as mentioned above. This study concluded that there are no significant associations between the meaning of life and academic performance. Psychometric analysis of the LAP-R revealed a Cronbach's alpha of .87 .

As far as we know, no more studies that have analyzed the structural validity and internal consistency of the LAP-R have been developed. 


\section{The Present Study}

The main objective of the present study was to analyze the factorial structure, reliability, invariance across gender, and absence/presence of assessment bias of a Spanish adaptation of the Turkish LAP-R (Erci 2008) in Chilean secondary students in $3 \mathrm{rd}$ and 4 th year. We hypothesised that the four-dimension structure proposed for this scale would be confirmed in the Chilean population, with an acceptable internal consistency, and that there would be invariance across gender.

\section{Method}

\section{Participants}

Participants were 2138 Chilean secondary students in 3rd and 4th year (1205 boys, $56.3 \%, 912$ girls, $42.6 \%$, and 8 others, $.3 \%)$. The sample was divided into two subsamples: Subsample 1, composed of 851 students and graduates (583 boys, $69 \%$, and 261 girls, $31 \%$, aged between 16 and 20 years, $M=18.2, S D=1.6$ ) from educational establishments in the Metropolitan region of Santiago de Chile, who answered the LAP-R via the web, and Subsample 2, composed of 1287 students ( 622 boys, $48.6 \%$, and 651 girls, $50.8 \%$, and 8 other, $.6 \%$, aged between 16 and 20 years, $M=18.2, S D=.6$ ). Table 1 shows the participants' sociodemographic and educational characteristics.

\section{Instrument}

The Life Attitude Scale-Revised (LAP-R; Erci 2008), which was described above, was used in the current study.

\section{Statistical Analyses}

Statistical analyses included: (1) the descriptive statistics of the LAP-R obtained for this study (mean, standard deviation, skewness and $\mathrm{Sk} / \mathrm{Se}$, kurtosis and $\mathrm{Ku} / \mathrm{Se}$ ); (2) a parallel analysis to determine the number of factors to extract; (3) an Exploratory Factor Analysis (EFA) carried out with Subsample $1(n=851)$ (Flora and Flake 2017); (4) a Confirmatory Factor Analysis (CFA) carried out with Subsample $2(n=1287)$. Since the LAP-R is an ordinal scale and it was not possible to assume multivariate normality, the Diagonally Weighted Least Squares (DWLS) method with robust estimation was performed; (5) the estimation of internal consistency using omega coefficient (McDonald 1999); (6) an Analysis of Variance (ANOVA) across gender (Putnick and Bornstein 2016).

Fit indices included both the Comparative Fit Index (CFI) and Tucker-Lewis Index (TLI), with values $\geq .90$ indicating acceptable fit and values $\geq .95$ indicating good model fit, as well as both the Root Mean Square Error of Approximation (RMSEA) and Standardized Root Mean Square Residual (SRMR), with values $\leq .08$ indicating acceptable model fit and values $\leq .05$ indicating good model fit (Hair et al. 2006).

The analyses were performed with the statistical package R, and the Psych packages (Revelle 2018) were used to perform the parallel analysis, the EFA and the internal consistency analysis, and lavaan (Rossel et al. 2019) to perform the MG -CFA.

\section{Procedure}

Participants were recruited through two channels: the first sample in an academic space of preparation for university life, and the second sample directly in their educational establishments, answering on paper.
Table 1 Participants' characteristics

\begin{tabular}{llllll}
\hline & & \multicolumn{2}{c}{ Subsample 1 } & $(n=851)$ & \multicolumn{2}{c}{ Subsample 2 $(n=1287)$} \\
\hline Variable & Group & $n$ & $\%$ & $n$ & $\%$ \\
Gender & Boys & 583 & 69.1 & 622 & 48.8 \\
& Girls & 261 & 30.9 & 651 & 51.1 \\
& Other & & & 8 & .60 \\
Level & 3rd & 143 & 16.8 & 1287 & 100 \\
& 4th & 422 & 49.6 & & \\
\multirow{3}{*}{ College } & Graduated & 285 & 33.5 & & 46.2 \\
& Public & 221 & 26.0 & 594 & 31.9 \\
& Private with public funding & 463 & 54.5 & 411 & 21.9 \\
& Private & 166 & 19.5 & 282 & 55.9 \\
& Humanistic & 768 & 90.4 & 719 & 44.1 \\
\hline
\end{tabular}


The LAP-R was translated into Spanish taking into account the ISPOR guidelines (Wild et al. 2005). First, two Chilean native translation specialists translated the LAP-R into Spanish. Then, the LAP-R underwent the reverse process (i.e., translated from Spanish into English) with Spanish speakers. All translators worked independently. Both versions were evaluated by the research team and subsequently discussed with four experts on the subject, two of whom are researchers on MiL in Latin America in the psychology area and the other two are researchers on topics of the meaning of life, who evaluated clarity, relevance and precision of each item of the LAP-R.

\section{Ethical Approval}

The confidentiality of the participants was protected and both the instruments and the protocols were reviewed by two ethics committees, one at the level of the sponsoring institution and the other from the Scientific Ethical Committee of the Catholic University of Chile (ID 180513001). Written informed consent was obtained from legally authorized representatives before the study. Likewise, the authors complied with APA ethical standards in the treatment of their participants.

\section{Results}

\section{Descriptive Analysis of the Chilean Version of the LAP-R}

Table 2 shows the descriptive statistics of the Chilean version of the LAP-R used in the present study. The averages for each item tended to be at the top of the scale, and the distributions were generally asymmetric, with a tendency to be biased towards the lowest scores on the scale. This is an important fact, as the assumption that the observed variables (items) are continuous and normally distributed is not confirmed on Likert scales, and could lead to estimation problems in the case of extremely skewed distributions, as is the case with the LAP-R scale (Rhemtulla et al. 2012).

\section{Exploratory Factor Analysis of the Chilean Version of the LAP-R}

For both the EFA and MGCFA, polychoric correlations were used (Baglin 2014; Flora and Flake 2017). Bartlett's sphericity test, $\chi_{(29)}^{2}=2237.9, p<.001$, and Kaiser-Meyer-Olkin's test, $\mathrm{KMO}=.95$, suggested the convenience of carrying out a factorial analysis. Then, a parallel analysis was performed (Horn 1965). Eigenvalues one, two, and three were found in the extracted simulated data, indicating a three-factor structure. Likewise, eigenvalue number three was related to the most obvious breakpoint in the sedimentation graph. Therefore, the three-factor solution was accepted (Fig. 1).

A considerable convergence was obtained between the theoretical model of the instrument and the empirical solution obtained (Table 3). The items belonging to the Coherence and Purpose domains converged on the same factor. On the other hand, the items that account for Goals (and challenges for the future) converged on the same factor. In the case of the items that were expected to account for individual Responsibility, the structure was observed for items 10, 12, 13,18 , and 25 , but not for items 3,7 , and 28 , which were associated with Goals.

\section{CFA of the Chilean Version for the LAP-R Obtained in the Present Study and Comparison with the Original Theoretical Model}

Three AFCs were carried out: (1) the first model was based on the predefined structure for the instrument; (2) in the second model, the structure based on the AFE presented above was used, to compare the adjustment levels between both models; (3) in the third model, re-specifications were included to improve the adjustment of the model. The initial sample ( $n=$ $1287)$ was reduced $(n=1159)$ due to loss of data in some items.

Suitable model fit indicators were obtained: $\chi_{(399)}^{2}=$ $2524.39, p<.001, \mathrm{CFI}=.98, \mathrm{TLI}=.98, \mathrm{RMSEA}=.068(90 \%$ CI $[.065, .070]), \mathrm{SRMR}=.058$ (Fig. 2). Factor loads ranged from .60 to .89 , except for item 9 (I would enjoy escaping from the routine of life). The high correlation between Purpose and Coherence is striking, indicating that both constructs are empirically indistinguishable in this instrument. In light of the results of the AFE and the parallel analysis previously presented, it was postulated that there would be a single factor associated with the items of the Consistency and Purpose constructs, and therefore it was assumed that there are three factors that explain the covariation of the items in the instrument.

The model obtained through the AFE was replicated (Fig. 3), showing adequate adjustment indices, better than the theoretical model, $\chi_{(402)}^{2}=2305.08, p<.001, \mathrm{CFI}=.98$, TLI $=.98$, RMSEA $=.064($ CI 90\% [.061, .066] $)$, $\mathrm{SRMR}=.055$.

In order to corroborate the association between item 28 and the Goals factor instead of the Responsibility factor, the model was re-specified including item 28 in the Responsibility factor, showing a worse adjustment than the model based on the AFE, $\chi_{(402)}^{2}=2530.55, p<.001, \mathrm{CFI}=.98, \mathrm{TLI}=.98$, $\mathrm{RMSEA}=.068(\mathrm{CI} 90 \%[.065, .070]), \mathrm{SRMR}=.058$. In this way, it is corroborated that the model proposed by the AFE fits better than the theoretical structure originally proposed.

The last re-specification of the model was (1) to eliminate item 9 (I would enjoy escaping from the routine of life) because, in addition to showing a low association with the Goals factor, the statement is very general and moves away from the 
Table 2 Descriptive statistics of the LAP-R

Item

1. Mis logros del pasado le han entregado sentido y propósito a mi vida/My previous achievements have given sense and purpose to my life

2. En mi vida tengo metas y objetivos claros/I have clear goals and objectives in my life

3. Considero muy importante la oportunidad de dirigir mi vida/I think the opportunity to direct my life is very important

4. He descubierto un propósito de vida satisfactorio/I have discovered a satisfying life purpose

5. El sentido de la vida es evidente en el mundo que nos rodea/The meaning of life is evident in the world around us

6. Me atraen las cosas nuevas y diferentes/New and different things appeal to me

7. Mis logros en la vida están en gran medida determinados por mi propio esfuerzo/My achievements in life are largely determined by my own efforts

8. He estado consciente del propósito todopoderoso y arrollador en el que mi vida se ha dirigido/I have been aware of the all-powerful and overwhelming purpose towards which my life has been directed

9. Disfrutaría escapar de la rutina de la vida/I would enjoy escaping the routine of life

10. Yo determino lo que ocurre en mi vida/I determine what happens in my life

11. Básicamente, estoy viviendo el tipo de vida que quiero vivir/Basically, I am living the kind of life I want to live

12. En relación a mi libertad de escoger, creo que soy absolutamente libre de tomar todas las decisiones en mi vida/Concerning my freedom to make choices, I believe I am absolutely free to take all the decisions in my life

13. Es posible para mí vivir mi vida en términos de lo que quiero hacer/It is possible for me to live my life in terms of what I want to do

14. Siento la necesidad de aventuras y de "mundos nuevos que conquistar"/I feel the need for adventure and "new worlds to conquer"

15. Sé hacia dónde va mi vida en el futuro/I know where my life is going in the future

16. Cuando pienso en mi vida, veo una razón por la cual estoy aquí/When I think of my life, I see a reason for me being here

17. Tengo una estructura que me permite entender o dar sentido a mi vida/I have a framework that allows me to understand or make sense of my life

18. Mi vida está en mis manos y yo la controlo/My life is in my hands and I am in control of it

19. En el logro de metas en la vida, me siento completamente realizado/In achieving life's goals, I feel completely fulfilled

20. Disfrutaría tener un nuevo desafío en mi vida ahora/I would enjoy having a new challenge in my life now

21. Tengo la idea que las partes de mi vida encajan en un patrón unificado/I think the different parts of my life fit together into a unified pattern

22. Espero algo emocionante en el futuro/I hope for something exciting in the future

23. Tengo una misión de vida que me entrega un sentido de dirección/I have a mission in life that gives me a sense of direction

24. Tengo claro entendimiento del significado mayor de la vida/I have a clear understanding of the ultimate meaning of life

25. Cuando se trata de asuntos de vida importantes, tomo mis propias decisiones/When it comes to important life matters, I make my own decisions

26. Tengo ganas de sacar más provecho de la vida de lo que he hecho hasta ahora/I am eager to get more out of life than I have so far

27. Estoy decidido(a) a alcanzar nuevas metas en el futuro/I am determined to achieve new goals in the future

28. Acepto la responsabilidad personal de las elecciones que he hecho en mi vida/I accept personal responsibility for the choices I have made in my life

29. Mi existencia personal está en orden y es coherente/My personal existence is orderly and coherent

30. Mi vida está llena de cosas buenas y emocionantes/My life is full of good and exciting things

\begin{tabular}{|c|c|c|c|c|}
\hline$M$ & $S D$ & $M d$ & Skewness & Kurtosis \\
\hline 5.34 & 1.49 & 6 & $-.95(.05)$ & $.56(.106)$ \\
\hline 5.83 & 1.42 & 6 & $-1.48(.05)$ & $1.98(.106)$ \\
\hline 6.51 & 0.91 & 7 & $-2.85(.05)$ & 10.85 \\
\hline 5.13 & 1.53 & 5 & $-.84(.05)$ & $.33(.106)$ \\
\hline 4.73 & 1.68 & 5 & $-.56(.05)$ & $-.38(.106)$ \\
\hline 5.98 & 1.18 & 6 & $-1.47(.05)$ & $2.70(.106)$ \\
\hline 6.10 & 1.14 & 6 & $-1.74(.05)$ & $3.78(.106)$ \\
\hline 4.90 & 1.58 & 5 & $-.74(.05)$ & $.15(.106)$ \\
\hline 6.17 & 1.23 & 7 & $-1.79(.05)$ & $3.33(.106)$ \\
\hline 5.55 & 1.40 & 6 & $-.96(.05)$ & $.57(.106)$ \\
\hline 4.72 & 1.66 & 5 & $-.55(.05)$ & $-.43(.106)$ \\
\hline 5.45 & 1.59 & 6 & $-.99(.05)$ & $.23(.106)$ \\
\hline 5.56 & 1.40 & 6 & $-1.08(.05)$ & $.91(.106)$ \\
\hline 5.76 & 1.33 & 6 & $-1.10(.05)$ & $.96(.106)$ \\
\hline 4.89 & 1.73 & 5 & $-.69(.05)$ & $-.29(.106)$ \\
\hline 5.01 & 1.76 & 5 & $-.73(.05)$ & $-.30(.106)$ \\
\hline 5.06 & 1.59 & 5 & $-.75(.05)$ & $-.04(.106)$ \\
\hline 5.35 & 1.58 & 6 & $-.92(.05)$ & $.27(.106)$ \\
\hline 4.40 & 1.63 & 5 & $-.40(.05)$ & $-.57(.106)$ \\
\hline 5.41 & 1.45 & 6 & $-.89(.05)$ & $.51(.106)$ \\
\hline 4.66 & 1.43 & 5 & $-.46(.05)$ & $.12(.106)$ \\
\hline 6.29 & 1.14 & 7 & $-2.25(.05)$ & $6.03(.106)$ \\
\hline 5.28 & 1.55 & 6 & $-.86(.05)$ & $.29(.106)$ \\
\hline 4.90 & 1.69 & 5 & $-.66(.05)$ & $-.25(.106)$ \\
\hline 5.68 & 1.25 & 6 & $-1.11(.05)$ & $1.44(.106)$ \\
\hline 6.30 & 1.08 & 7 & $-2.11(.05)$ & $5.41(.106)$ \\
\hline 6.48 & 0.98 & 7 & $-2.70(.05)$ & $9.30(.106)$ \\
\hline 6.27 & 1.03 & 7 & $-1.95(.05)$ & $5.13(.106)$ \\
\hline 5.15 & 1.54 & 5 & $-.85(.05)$ & $.35(.106)$ \\
\hline 5.04 & 1.58 & 5 & $-.67(.05)$ & $-.11(.106)$ \\
\hline
\end{tabular}

Note. In parenthesis, the standard deviation 


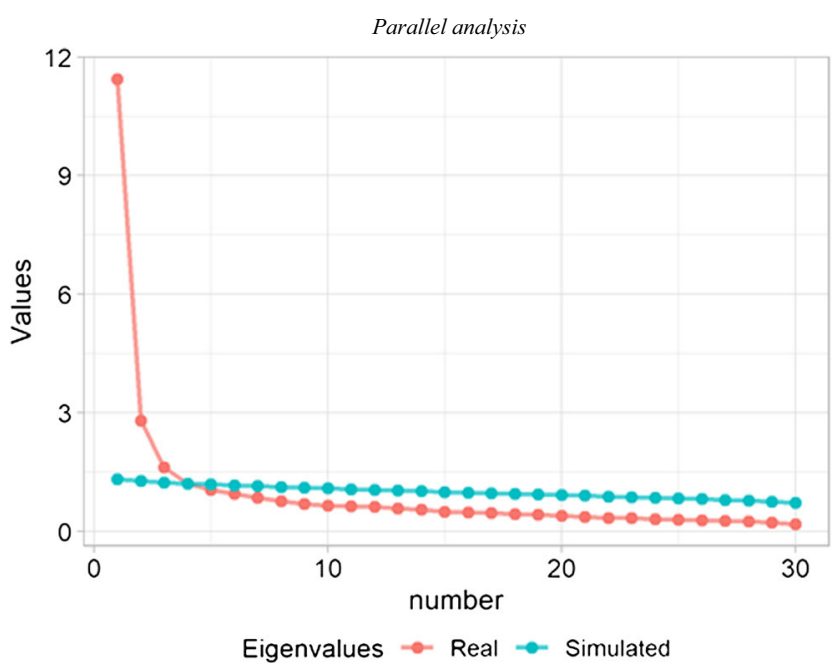

Fig. 1 Parallel analysis

definition of the construct, and (2) given the high correlation between the factors, it was assumed that this could account for an omitted common cause, which in this case would be a second-order factor. Fig. 4 presents the final model.

The model adjustment indicators presented in Fig. 3 were adequate, $\chi_{(374)}^{2}=1986.74, p<.001, \mathrm{CFI}=.99$, TLI $=.98$, RMSEA $=.061$ (CI 90\% [.058, .064]), SRMR $=.051$, indicating that it is sustainable that the correlation between the factors could be explained through the use of a second-order factor, which was called Meaning.

\section{Internal Consistency of the Chilean Version of the LAP-R Obtained in the Present Study}

The Omega coefficient (McDonald, 1999), which is based on factor analysis, was used to separate the shared variance between the items from the single variance (which contains the measurement error). Table 4 shows the $w$ h (which indicates the variance explained by a single factor) and $\omega t$ (which indicates the variance explained by multiple factors).

\section{Invariance across Gender of the LAP-R Obtained in the Present Study}

Table 5 shows the MGCFA (Putnick and Bornstein 2016) of the LAP-R. The absolute adjustment indicator worsened, especially in the restriction of factorial load equality. The adjustment indicators showed that this is explained by multiple items that would load the factors in different ways, especially item 27 (I am determined to achieve new goals in the future), whose load is stronger for women; and item 26 (I am eager to get more out of life than I have so far), whose load is stronger for men. However, given the large sample size, other adjustment indicators were observed, which showed, in all cases, an adequate adjustment of the model, assuming that, despite
Table 3 Final solution obtained in the present study for the Chilean version of the LAP-R

\begin{tabular}{|c|c|c|c|}
\hline Item & Factor 1 (Coherence) & Factor 2 (Goals) & $\begin{array}{l}\text { Factor } 3 \\
\text { (Responsibility) }\end{array}$ \\
\hline 4 & .836 & & \\
\hline 16 & .835 & & \\
\hline 17 & .809 & & \\
\hline 15 & .751 & & \\
\hline 23 & .761 & & \\
\hline 2 & .653 & & \\
\hline 24 & .647 & & \\
\hline 8 & .607 & & \\
\hline 19 & .594 & & \\
\hline 21 & .582 & & \\
\hline 1 & .572 & & \\
\hline 5 & .558 & & \\
\hline 29 & .555 & & \\
\hline 11 & .516 & & \\
\hline 30 & .481 & & \\
\hline
\end{tabular}

.642

$22 \quad .637$

$26-628$

$9-\quad .601$

$14 \quad .574$

$6 \quad .569$

$3 \quad .482$

$20 \quad .434$

$28 \quad .424$

$7-400$

$12 \quad .817$

$18 \quad .734$

$10 \quad .637$

$13 \quad .558$

$25 \quad 395$

$\begin{array}{llll}\% \mathrm{EV} & 22.9 \% & 10.8 \% & 8.6 \%\end{array}$

Note. The Principal Axes method and also the Minimal Residual method were implemented, in both cases using Oblimin rotation, getting exactly the same results; EV = Explained Variance

some differences, the items were similarly associated with men and women in the constructs under analysis.

Given that there is evidence of invariance in the instrument, the averages of men and women were compared. MannWhitney's test showed significant differences in both the Coherence and Meaning dimensions (Table 6).

\section{Discussion}

The purposes of the present study were to analyse the factorial structure, reliability, and invariance across gender of a 
Theoretical model for the LAP

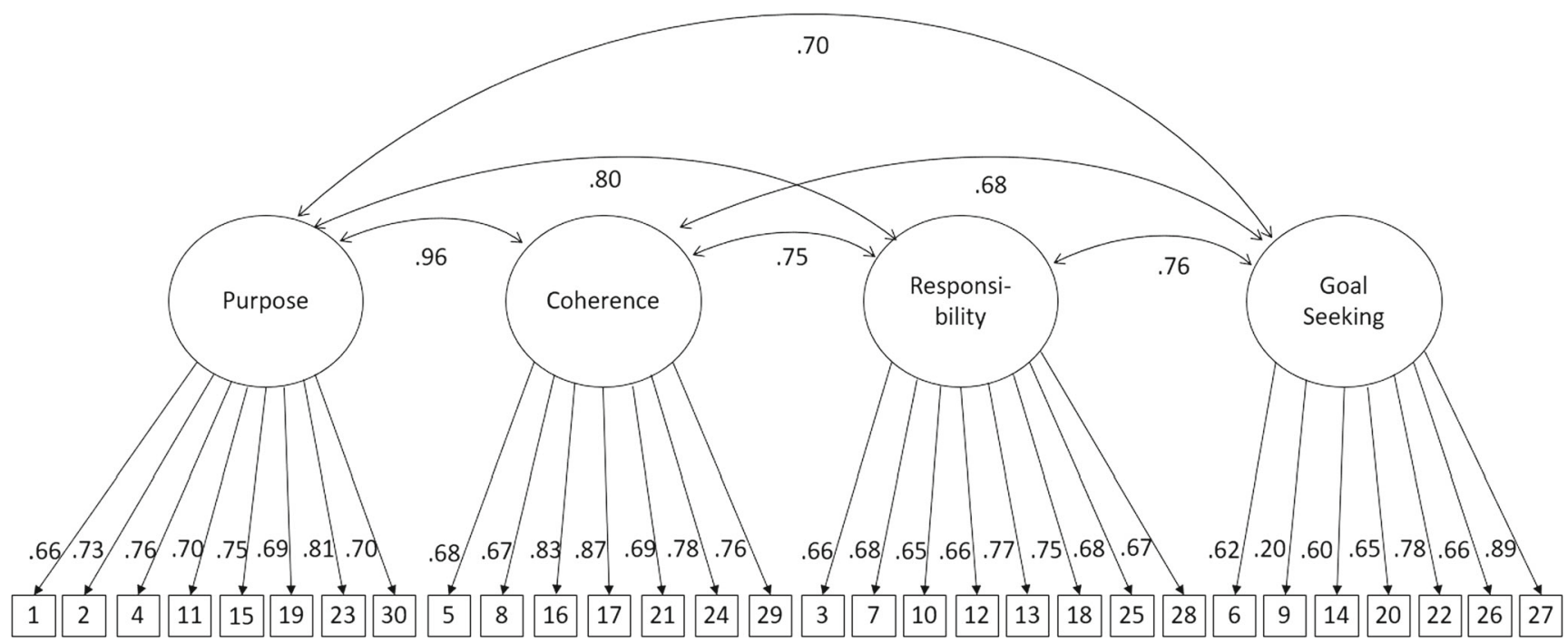

Fig. 2 Theoretical model for the LAP

Spanish adaptation of the Turkish LAP-R (Erci 2008) in Chilean secondary students in $3 \mathrm{rd}$ and 4 th year. We hypothesised that the four-dimension structure proposed for this scale would be confirmed in the Chilean population, with an acceptable internal consistency, and that there would be invariance across gender.

\section{Factorial Structure of the Chilean LAP-R}

The results showed that the LAP-R is a scale with an acceptable structural validity. These results are consistent with the original theoretical model proposed by Erci (2008), although some differences found must be highlighted. In particular, an interesting finding is a clear difficulty distinguishing the Coherence and Purpose domains, indicating that these constructs may not be empirically separable, since coherence refers to having a consistent understanding of oneself, others and life, therefore it could be understood as a requirement to approach the purpose, that is, the ability to set vital goals, a mission in life and a sense of direction. From this perspective, the difficulty differentiating the two constructs may lie in the interdependence between the two, that is, to have life goals and a sense of direction from the past, the present, and the future requires a thorough understanding of oneself. This, however, does not seem to be a problem, to the extent that a high conceptual association between both constructs can be stated (Anagnostopoulos et al. 2011). These findings suggest that there is evidence against the hypothesised factor structure, although in this case 3 factors are considered and not 4 as it was postulated in the beginning. It is interesting to note that Mehnert and Koch (2008) obtained a strong overlap between the Purpose and the Coherence dimensions, $r=.72$, and stated

Model for the LAP-R obtained in the present study

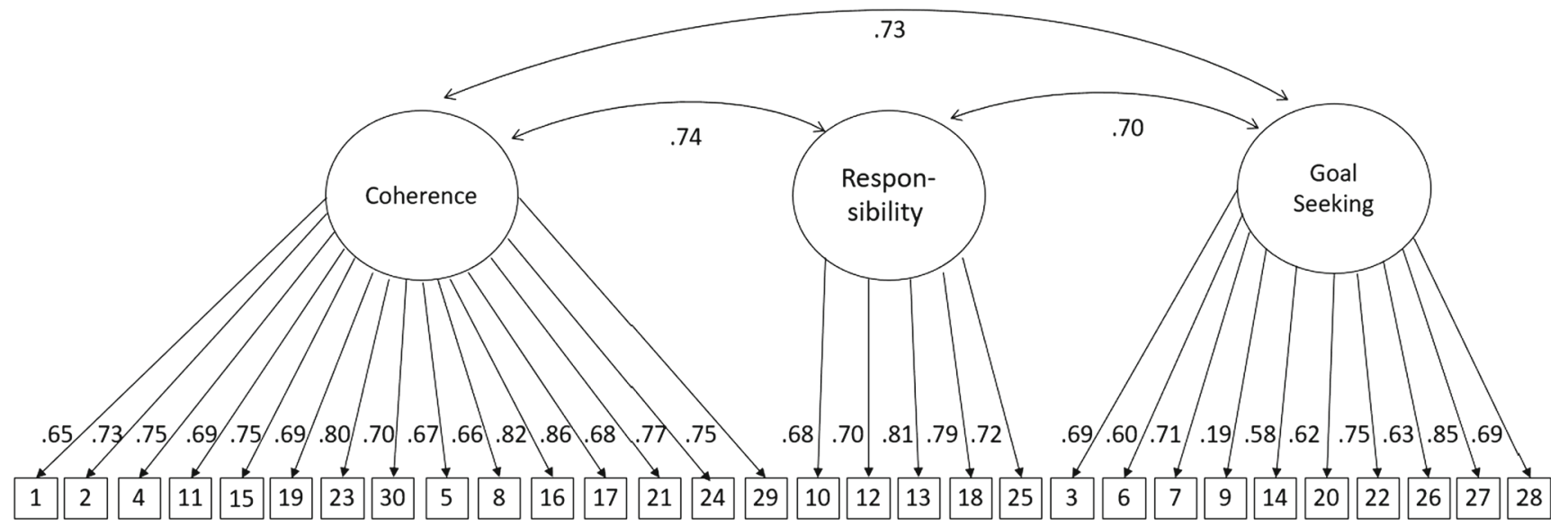

Fig. 3 Model for the LAP-R obtained in the present study 


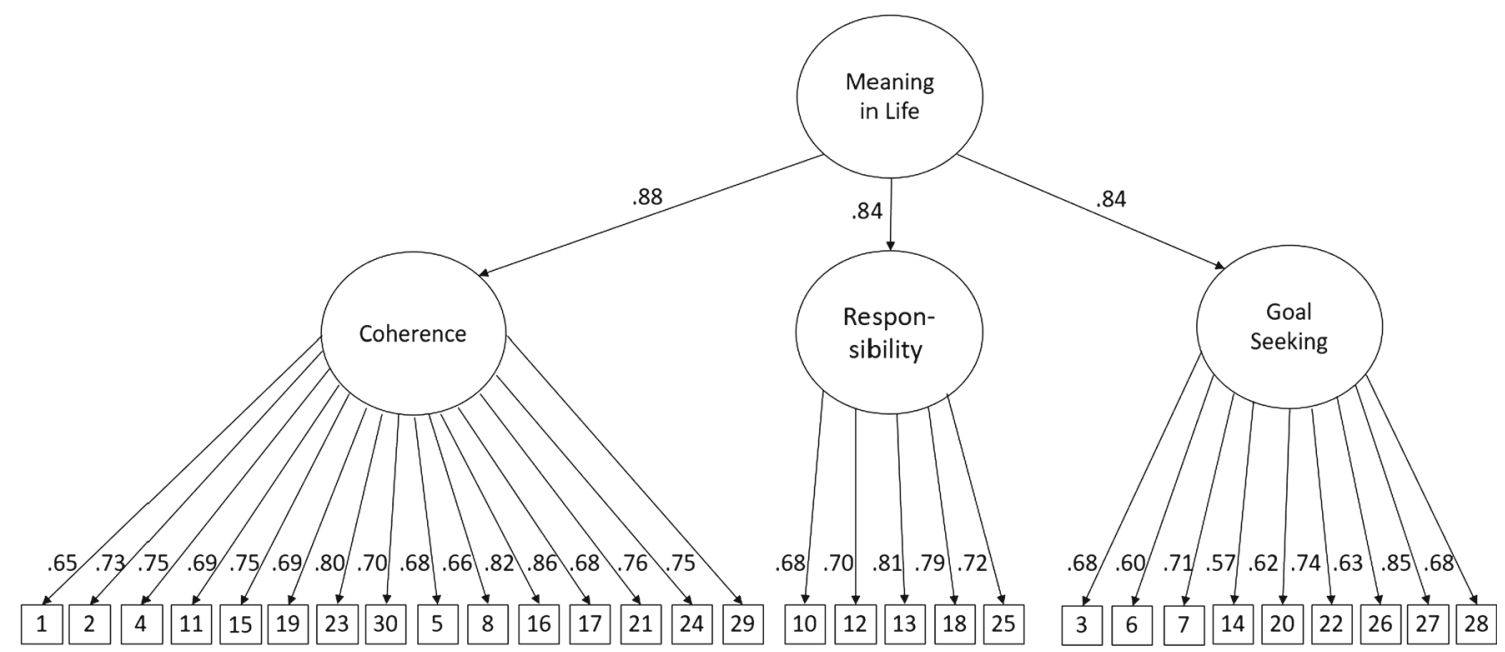

Fig. 4 Second-Order factor model for the LAP-R obtained in the present study

that it could be explained by the fact that both dimensions were hypothesized to constitute the construct of personal meaning.

On the other hand, items 3 (I think the opportunity to direct my life is very important), 7 (My achievements in life are largely determined by my own efforts), and 28 (I accept personal responsibility for the choices I have made in my life), which were initially supposed to be mostly associated with the Responsibility dimension, turned out to be associated with the Goals factor. This is an interesting finding since these items refer to personal responsibility in choices, which seems to be more related to the motivation to achieve new challenges (Goals factor), than to the factor that was initially called Responsibility. When considering the items with a higher load in this factor, which are item 12 (Concerning my freedom of choice, I think I am absolutely free to make all the decisions in my life) and item 18 (My life is in my hands and I am in control of it), the factor rather accounts for the beliefs and experience regarding the ability to make decisions, which may not be directly linked to the responsibility, but rather to the individual conditions to assume certain responsibilities in front of the definition and projection of meaning as such.

Table 4 Internal consistency of the Chilean adaptation of the LAP-R

\begin{tabular}{|c|c|c|c|c|c|c|}
\hline \multirow[b]{2}{*}{ Factor } & \multicolumn{2}{|c|}{ Total Sample } & \multicolumn{2}{|c|}{ Subsample 1} & \multicolumn{2}{|c|}{ Subsample 2} \\
\hline & $w_{\mathrm{h}}$ & $\omega_{\mathrm{t}}$ & $\omega_{\mathrm{h}}$ & $w_{t}$ & $\omega_{\mathrm{h}}$ & $\omega_{t}$ \\
\hline Coherence & .86 & .95 & .81 & .95 & .87 & .95 \\
\hline Responsibility & .81 & .88 & .79 & .87 & .79 & .88 \\
\hline Goals & .74 & .90 & .70 & .88 & .76 & .91 \\
\hline
\end{tabular}

Note. $\omega_{\mathrm{h}}=$ Omega Hierarchical; $\omega_{\mathrm{t}}=$ Omega Total
Regardless of the discussion about the theoretical characteristics of meaning as an attribute and how its structure should be, the high level of association between the subdimensions and the fact that the adjustment indicators were adequate in the various models, shows that the instrument has adequate psychometric properties to be used in more complex analyses, especially making use of a second-order variable that accounts for the global measure of MiL in the Chilean population.

Regarding the construct of responsibility, evidence was found both for and against the hypothesised model. The association of item 3 (I think the opportunity to direct my life is very important) with the Goals factor, although not particularly high, could indicate that the item emphasizes more the idea of leading life towards objectives or projects, rather than emphasizing the idea of self-determination and responsibility in front of one's own decisions (Responsibility domain). This idea could be better expressed by item 12 (Concerning my freedom to make choices, I believe I am absolutely free to take all the decisions in my life), which is the item most associated with the Responsibility factor. On the other hand, item 7 (My achievements in life are largely determined by my own effort) refers to a belief regarding the ability to achieve objectives and goals, rather than the use of freedom. Regarding item 28 (I accept personal responsibility for the choices I have made in my life), it is not clear why it is associated with the Goals factor instead of the Responsibility factor. It is possible to observe that the items that are clearly associated with the factor (10, 12,13 , and 18) are statements regarding the ability to choose, that is to say, they point to perception in the ability to make decisions, which could be considered as self-determination, while item 28 refers to the experience of responsibility towards the choices already made. This could lead us to suppose that the sense of responsibility appears rather associated with the choice of challenges or objectives and that the factor 
Table 5 Model comparison for invariance analysis across gender

\begin{tabular}{|c|c|c|c|c|c|c|c|c|c|}
\hline & $\chi^{2}(d f)$ & $\Delta \chi^{2}(\Delta d f)$ & $p$ & CFI & RMSEA $[90 \% \mathrm{CI}]$ & SRMR & $\Delta \mathrm{CFI}$ & $\triangle \mathrm{RMSEA}$ & $\triangle \mathrm{SRMR}$ \\
\hline Total & $1714.009(321)$ & - & $<.001$ & .991 & $.061[.058, .064]$ & .049 & & & \\
\hline Men & $1038.820(321)$ & - & $<.001$ & .991 & $.063[.059, .067]$ & .054 & & & \\
\hline Women & $1015.802(321)$ & - & $<.001$ & .990 & $.061[.056, .065]$ & .053 & & & \\
\hline Configural & $2054.622(642)$ & - & - & .991 & $.062[.059, .065]$ & .054 & & & \\
\hline Metric & $2275.741(668)$ & $221.119(26)$ & $<.001$ & .990 & $.065[.062, .067]$ & .057 & .001 & .003 & .003 \\
\hline Strong & 2321.565 (799) & $45.823(131)$ & .999 & .990 & $.057[.055, .060]$ & .054 & .000 & .008 & .003 \\
\hline Strict & $2467.530(826)$ & $145.966(27)$ & $<.001$ & .989 & $.058[.056, .061]$ & .057 & .000 & .001 & .003 \\
\hline
\end{tabular}

Note. Item 6 was dropped from these analyses, since the women's group did not have data in every response category, so the model was not estimable

generated with items $10,12,13$, and 18 , rather points to selfdetermination, that is, to the ability to lead one's life and make decisions. Given the lack of clarity regarding the association of item 28 with the other factors, some options will be explored in the AFC.

It is interesting to note that the role of a facet like "acceptance of death" probably varies across the lifespan and may not be a key component of having a mature sense of meaning during adolescence, whereas other aspects (such as developing a sense of autonomy and agency) are clearly more salient earlier in the lifespan. Further studies should analyze this issue in different populations.

Finally, it is relevant to discuss the deleting of item 9 ( $I$ would enjoy escaping the routine of life) because, in addition to showing a low association with the Goals factor, this item is deemed to be a reagent that does not adequately discriminate between age ranges, since the breakdown of the routine or the search for new experiences is a differentiating element of adolescence as an age range (Delgado, 2015).

\section{Internal Consistency of the Chilean LAP-R}

The factorial loads of the LAP-R were adequate, all over $\lambda=.60$, except for item 14 (I feel the need for adventure and 'new worlds to conquer), whose load was $\lambda=.56$. Likewise, the internal consistency of the instrument is adequate, considering that the wh ranges between .70 and .81 for Sample 1, and ranges from .76 to .87 for Sample 2, indicating that a high percentage of the variance observed in the items is shared with the latent variable. These values are consistent with other research, such as Erci (2008), who reported an internal consistency $(\omega)$ for the LAP-R between .73 and .82, with acceptable item-total correlations, except for item 15, which for this study did not present a mismatch. The item-total correlations ranged from .29 to .72 for the remaining 47 items. However, like the current study, Cronbach's alphas of the two domains of Death Acceptance and Existential Vacuum were no more than 0 to 70 , and these dimensions were removed from the scale.

\section{Invariance across Gender of the Chilean LAP-R}

The analysis of invariance distinguished by gender allows us to assume that the instrument measures the construct in men and women in a similar way. The absence of deterioration in the model when restricting factor loads and thresholds suggests that the way latent variables are associated with the items is similar for men and women, so that the differences observed in the behaviour of the items are explained by differences in latent variables and not differences in the interpretation and/or meaning of the items. This makes it possible to compare the averages between men and women at the level of latent variables to establish differences between the two groups (Putnik and Bornstein 2016). Therefore, the level of strict invariance reached allows us to maintain that the variance not explained by the latent variables (uniqueness) is similar in both groups, so the use of this instrument can be justified to make comparisons between male and female adolescents at the same level of observed scores.

\section{Conclusions}

The model for LAP-R obtained shows adequate psychometric properties. The results obtained allow us to explore and discuss relevant aspects regarding meaning as a domain of human experience. The difficulty of having scales that address the question of meaning in tune with young populations seems to be evident in the Latin American context, hence the relevance of this proposal that harmonizes the validation of a scale that can be very useful not only in Chile but in neighbouring countries. At the same time, having a scale like LAP-R to apply in our population makes it possible to explore populations that are terminally or seriously ill, for which it has been extensively applied in other contexts.

Considering the scarce literature that has explored the characteristics of this variable, this work can be a starting point for further investigations, as well as for the analysis of the foundational theory of the measurement of this construct. 
Table 6 Gender comparison in the LAP-R dimensions

\begin{tabular}{|c|c|c|c|c|c|c|c|c|c|c|}
\hline \multirow[b]{2}{*}{ LAP-R dimensions } & \multicolumn{2}{|c|}{ Men $(n=636)$} & \multicolumn{2}{|c|}{$\begin{array}{l}\text { Women } \\
(n=655)\end{array}$} & \multicolumn{2}{|c|}{$\begin{array}{l}\text { Total } \\
(n=1291)\end{array}$} & \multirow[t]{2}{*}{$p^{*}$} & \multicolumn{3}{|c|}{$\begin{array}{l}\text { Wilcoxon-Mann- } \\
\text { Whitney Test }\end{array}$} \\
\hline & $M$ & $S D$ & $M$ & $S D$ & $M$ & $S D$ & & $W$ & $p$ & $d$ \\
\hline Coherence & 5.067 & 1.170 & 5.007 & 1.147 & 5.037 & 1.158 & .369 & 185,872 & .325 & .028 \\
\hline Responsibility & 5.561 & 1.144 & 5.372 & 1.169 & 5.465 & 1.161 & .004 & 220,799 & .001 & .091 \\
\hline Goal Seeking & 5.990 & .862 & 6.081 & .804 & 6.037 & .834 & .053 & 182,633 & .039 & .058 \\
\hline Meaning & 5.479 & .934 & 5.419 & .910 & 5.448 & .922 & .269 & 172,872 & .210 & .036 \\
\hline
\end{tabular}

*Student's $t$ test

\section{Limitations of the Present Study}

At least three limitations are observed, which could become potential spaces of inquiry. The first limitation refers to the characteristics of the population, under the assumption that we worked exclusively with students belonging to the metropolitan region, although it is the largest region in population and it represents the reality of a highly developed urban area, it does not welcome students who represent the rural world, and that given the contextual, situated and dynamic character of the construction of meaning can present variations. Therefore, to examine the stability and replicability of the structure obtained in this article, it is necessary to continue providing empirical evidence on differences such as age range and religious orientation, among others.

A second limitation is related to the access of both populations that were an object of study, as they were contacted through various means. The first sample participated in the study through an online questionnaire that was shared by their preparatory study centre for higher education and left to the students' decision and discretion, unlike those in sample two who were directly consulted in their educational establishments. This subtle difference could presuppose a greater motivation for the first sample to answer without regulatory mechanisms external to the questionnaire.

A third limitation refers to the use of self-report instruments, since the data reported by the subjects themselves can influence the validity of the data when affected by the subject's attributional style, exaggeration and selective memory, among others, thus being difficult to verify.

\section{Suggestions for Further Research}

In the current study, the EFA showed a tri-dimensional factorial structure for the LAP-R. This result raises a question about the reason that may have conditioned that structure. Could it be explained as an effect of the sample size in our study, which is much larger than then samples used in most past research, or as an effect of some sociodemographic characteristics of the participants examined, which are different to the examined in previous studies? It would be interesting to assess the psychometric properties of the LAP-R for different age, ethnical, and social-cultural groups. The aspects become relevant to provide on a sensitive scale to the diverse cultural realities of Latin American countries that advance in increasing multiculturalism, in early ageing and geographic decentralization, as well as it is the relevance of cross-cultural studies and with other populations, for example, adults, the elderly, the disabled and even children.

A second aspect is to enrich the use of this scale with qualitative dimensions that verify or contradict the understanding of the different constructs that are at the base of the scale.

Finally, a space of inquiry is opened that links the use of this scale with other instruments that capture dimensions of social well-being and that allow to compare relationships between meaning and other variables of psychosocial adjustment, especially in young people.

Acknowledgements This article emerged thanks to the financial support given by Fondecyt through the project $N^{\circ} 11180720$, "Characterization of the project and sense of life from eleventh grade until graduation, according to the financial source and the modality of schools: The relations with academic achievement, retentions in schools, life trajectories and perception of the educational actors in its construction".

Data Availability The datasets generated during and/or analysed during the current study are available from the corresponding author on reasonable request.

\section{Compliance with Ethical Standards}

Conflict of Interest We have no known conflict of interest to disclose.

Open Access This article is licensed under a Creative Commons Attribution 4.0 International License, which permits use, sharing, adaptation, distribution and reproduction in any medium or format, as long as you give appropriate credit to the original author(s) and the source, provide a link to the Creative Commons licence, and indicate if changes were made. The images or other third party material in this article are included in the article's Creative Commons licence, unless indicated otherwise in a credit line to the material. If material is not included in the article's Creative Commons licence and your intended use is not permitted by statutory regulation or exceeds the permitted use, you will need to obtain 
permission directly from the copyright holder. To view a copy of this licence, visit http://creativecommons.org/licenses/by/4.0/.

\section{References}

Ackerman, M. M. (2013). Relationship between student purpose in life and performance on New Mexico standards based assessment (doctoral dissertation). Minneapolis, Minnesota: Walden University.

Anagnostopoulos, F., Slater, J., Fitzsimmons, D., \& Kolokotroni, P. (2011). Exploring global meaning in Greek breast cancer patients: Validation of the life attitude profile-revised (LAP-R). Psycho-oncology, 20(4), 419-427. https://doi.org/10.1002/pon.1755.

Baglin, J. (2014). Improving your exploratory factor analysis using ordinal data: A demonstration using FACTOR. Practical Assessment, Research and Evaluation, 19(5). https://doi.org/10.7275/dsep-4220.

Burrow, A., \& Hill, P. (2011). Purpose as a form of identity Capital for Positive Youth Adjustment. Developmental Psychology, 47(4), 1196-1206. https://doi.org/10.1037/a0023818.

Burrow, A., O’Dell, A., \& Hill, P. L. (2010). Profiles of a developmental asset: Youth purpose as a context for hope and well-being. Journal of Youth and Adolescence, 39, 1265-1273. https://doi.org/10.1007/ s10964-009-9481-1.

Cotton, K., Finch, H., \& Talib, T. (2010). Purpose in life among high ability adolescents. High Ability Studies, 21(2), 133-145. https://doi. org/10.1080/13598139.2010.525339.

Damon, W., Menon, J., \& Cotton, K. (2003). The development of purpose during adolescence. Applied Developmental Science, 7(3), $119-128$.

DeWitz, J., \& Woolsey, L. W. (2009). College student retention: An exploration of the relationship between self-efficacy beliefs and purpose in life among college students. Journal of College Student Development, 50(1), 19-34. https://doi.org/10.1353/csd.0.0049.

Erci, B. (2008). Meaning in life for patients with cancer: Validation of the life attitude profile-revised scale. Journal of Advanced Nursing, 62(6), 704-711. https://doi.org/10.1111/j.1365-2648.2008.04658.x.

Flora, D. B., \& Flake, J. K. (2017). The purpose and practice of exploratory and confirmatory factor analysis in psychological research: Decisions for scale development and validation. Canadian Journal of Behavioural Science/Revue Canadienne Des Sciences du Comportement, 49(2), 78-88.

García-Alandete, J. (2014). Factor analysis of the Spanish version of the Purpose-in-Life test according to age and gender. Pensamiento Psicológico, 12(1), 83-98. https://doi.org/10.11144/javerianacali. ppsi12-1.afve.

García-Alandete, J., Gallego, B., Pérez, S., \& Marco, J. H. (2019). Meaning in life among adolescents: Factorial invariance of the purpose in life test and buffering effect on the relationship between emotional dysregulation and hopelessness. Clinical Psychology \& Psychotherapy, 26(1), 24-34. https://doi.org/10.1002/cpp.2327.

Hair, J. F., Anderson, R. E., Tatham, R. L., \& Black, W. C. (2006). Multivariate Data Analysis (6th ed.). Upper Saddle River, NJ: Pearson Prentice Hall.

Hodges, S., \& Crowe, A. (2014). Attitudes of college students towards purpose in life and self-esteem. International Journal of Existential Positive Psychology, 5(1), 124-131.

Horn, J. L. (1965). A rationale and test for the number of factors in factor analysis. Psychometrika, 30, 179-185. https://doi.org/10.1007/ bf02289447.

Lagos, F., \& Palacios, F. (2008). Orientación Vocacional y Profesional en Colegios de Bajo Nivel Socioeconómico: Percepciones de orientadores y estudiantes [Vocational and Professional Guidance in Low Socioeconomic Schools: Perceptions of counselors and students]. Calidad en la Educación, 28, 204-243. https://doi.org/ 10.31619/caledu.n28.209.

Makola, S. (2014). The importance of a sense of meaning in higher education: Review of literature studies. Journal of Educational Sciences \& Psychology, 4(2), 37-45.

Malika, M., Nordinb, N., Zakariac, A., \& Sirund, N. (2013). An exploratory study on the relationship between life satisfaction and academic performance among undergraduate students of UiTM, Shah Alam. Procedia-Social and Behavioral Sciences, 90, 334-339. https://doi.org/10.1016/j.sbspro.2013.07.099.

Martínez, L. (2007). Mirando al futuro: desafíos y oportunidades Para el desarrollo de los adolescentes en Chile [looking to the future: Challenges and opportunities for the development of adolescents in Chile]. Psykhe, 16(1), 3-14. https://doi.org/10.4067/s071822282007000100001.

McDonald, R. P. (1999). Test theory: A unified treatment. Hillsdale, MI: Erlbaum.

Mehnert, A., \& Koch, U. (2008). Psychometric evaluation of the German version of the life attitude profile-revised (LAP-R) in prostate cancer patients. Palliative Supportive Care, 6(2), 119-124. https://doi.org/ $10.1017 / \mathrm{s} 1478951508000199$.

Meraviglia, M. G. (2004). The effects of spirituality on well-being of people with lung cancer. Oncology Nursing Forum, 31(1), 89-94. https://doi.org/10.1188/04.onf.89-94.

Putnick, D., \& Bornstein, M. (2016). Measurement invariance conventions and reporting: The state of the art and future directions for psychological research. Developmental Review, 41, 71-90. https:// doi.org/10.1016/j.dr.2016.06.004.

Quiceno, J. M., \& Vinaccia, S. (2014). Satisfacción con la Vida según la edad, escolaridad y tiempo del diagnóstico en pacientes reumáticos [satisfaction with life according to age, schooling, and time of diagnosis in rheumatic patients]. Psicología y Salud, 24(2), 157-165.

Reker, G. T. (1992). Manual of the life attitude profile-revised. Peterborough, Ontario: Student Psychologists Press.

Reker, G. T., \& Peacock, E. J. (1981). The life attitude profile (LAP): A multidimensional instrument for assessing attitudes toward life. Canadian Journal of Behavioural Science, 13(3), 264-273. https:// doi.org/10.1037/h0081178.

Revelle, W. (2018). Psych: Procedures for Personality and Psychological Research [software]. ILL: Evanston https://CRAN. R-project.org/package $=$ psych.

Rhemtulla, M., Brosseau-Liard, P., Savalei, V., Appelbaum, M. I., \& Maxwell, S. E. (2012). When can categorical variables be treated as continuous? A comparison of robust continuous and categorical SEM estimation methods under suboptimal conditions. Psychological Methods, 17(3), 354-373. https://doi.org/10.1037/ a0029315.supp.

Rodríguez, C., \& Padilla, G. (2016). Trayectoria escolar y ranking: Valoraciones y estrategias institucionales en el nuevo escenario de selección universitaria [school career and ranking: Institutional evaluations and strategies in the new scenario of university selection]. Estudios Pedagógicos, 42(3), 313-326. https://doi.org/10.4067/ s0718-07052016000400017.

Salvatierra, L., Aracena, M., Ramírez, P., Reyes, L., Yovane, C., Orozco, A., \& Krausse, M. (2004). Autoconcepto y proyecto de vida: Percepciones de adolescentes embarazadas de un sector periférico de Santiago, participantes de un programa de educación para la salud [Self-concept and life project: Perceptions of pregnant adolescents from a peripheral sector of Santiago, who participated in a health education program]. Revista de Psicología, 14(1), 141-152.

Weiss, E. (2012). Los estudiantes Como jóvenes [students as youth]. Perfiles Educativos, 34(135), 134-148. https://doi.org/10.22201/ iisue.24486167e.2012.135.29175.

White, K., Wagener, L., \& Furrow, J. (2010). What am I here for?: A qualitative examination on the expression, development and integration of purpose in at-risk and thriving male adolescents. 
International Journal of Existential Psychology \& Psychotherapy, $3(1), 1-16$.

Wild, D., Grove, A., Martin, M., Eremenco, S., McElroy, S., VerjeeLorenz, A., \& Erikson, P. (2005). Principles of good practice for the translation and cultural adaptation process for patient-reported outcomes (pro) measures: Report of the ISPOR task force for translation and cultural adaptation. Value in Health, 8(2), 94-104.

Yeager, D. S., \& Bundick, M. J. (2009). The role of purposeful work goals in promoting meaning in life and in schoolwork during adolescence. Journal of Adolescent Research, 24(4), 423-452. https://doi.org/10.1177/0743558409336749.

Zhang, J., \& Li, X. (2016). Study of life education for college freshmen in China. International Education Studies, 9(2), 75-80. https://doi.org/ 10.5539/ies.v9n12p75.

Publisher's note Springer Nature remains neutral with regard to jurisdictional claims in published maps and institutional affiliations. 